\title{
An Experimental Study of Energy Dissipation of Sea Grass in a Dam Break Flume
}

\author{
Cheng Chen ${ }^{*}$, Fangyu Wang ${ }^{2}$
}

${ }^{1}$ College of Civil Engineering, Fuzhou University, Fuzhou 350108, China

${ }^{2}$ College of Harbour, Coastal and Offshore Engineering, Hohai University, Nanjing 210098, China

*to whom all correspondence should be addressed: e-mail: chencheng_1117@163.com

\section{GRAPHICAL ABSTRACT}

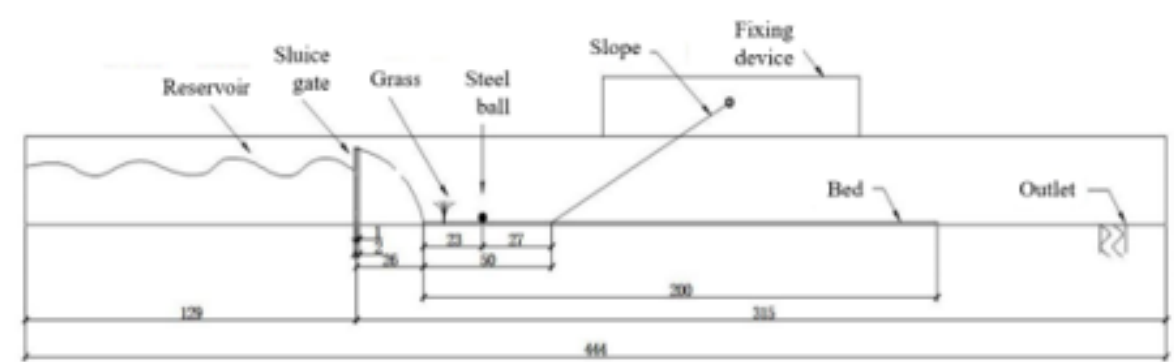

\begin{abstract}
An experimental study was carried out to investigate the energy dissipation characteristics of sea grass in a dam break flume. Dam break flows were generated in a flume. A steel ball was subjected to the dam break flow, and then climbed on a slope. Artificial sea grass was used as the energy dissipation plant. In the study, the characteristics (such as wave height, wave velocity, Froude number) of the dam break flow were investigated, the ball subjected to the dam break flow was observed, some impact factors of ball climbing height were explored. Results show that, the ball climbing height increases with increasing reservoir water level and decreasing ball diameter. The relative ball climbing height decreases with increasing relative distance and increasing relative grass height. The relative ball climbing height shows logarithmic correlation with relative reservoir water level. The energy dissipation coefficient of the sea grass changed with reservoir water level, with the average value of 0.34 in this study.
\end{abstract}

Keywords: Dam break, Sea grass, Steel ball, Energy dissipation.

\section{Introduction}

A dam break flow is caused by a sudden collapse of the reservoir, i.e. a sudden release of water, leading huge damages to human lives and structures. Therefore, the research on energy mitigation of the dam break flow is important for the hydraulic engineering (Zhao et al., 2020).

Tsunami surges are found to be similar to dam-break flows, and the analytical solution for the dam-break flow agrees well with the tsunami field data (Chanson H, 2006). Numerical models for tsunami generation and inundation were validated using a dam break model on the sloping beach (Damarnegara et al., 2021). Mizuno et al. (2021) simplify tsunami run-up as three-dimensional dam-break problems where the collapse of a water column owing to gravity moves in a slope and impacts on two buildings. Dam-break waves with different hydrodynamic conditions and initial configurations were simulated as large tsunamis in the study of coastal 
engineering (Hafen et al., 2021). Therefore, dam-break flows were usually simulated as tsunami surges in the experiments.

When the tsunami came ashore, the solid floating objects such as wood, containers, and vehicles would cause serious damages to onshore structures (Cao, 2020; Zhu et al., 2020). The related researches were carried out by scholars. Mizutani et al. (2005) found that the speed of floating objects on the shore was proportional to the propagation speed of the waves when the waves were relatively small, but it was a constant when the waves were large. Jing et al. (2003) simulated the generation of tsunami and subsequent wave propagation in a threedimensional numerical wave tank with the ALE finite element method, and the interaction between floating objects and onshore buildings were observed. Chen et al. (2020) conducted an experiment on the dam break flow impacts on balls climbing on slopes, and found that the maximum ball climbing height is a function of the dam break flow inundation height, the ball density, and the ball diameter. Yeom et al. (2009) use the LSDYNA collision model with reduced computational load to analyze the generation and propagation of tsunami and object drift. The effectiveness of the model was verified by measured data. Yeom et al. (2008) proposed a calculation method to estimate the collision time and collision force of containers under the effect of tsunami. The experimental results showed that the simulation performance of the drift container on rising wave is in good agreement with the laboratory experimental results. Therefore, under the impact of the tsunami wave, the floating object showed different movement patterns according to the tsunami wave and its own characteristics. To mitigate the tsunami wave or the dam break flow, the plants were usually used in the laboratory. Kouwen et al. (1969) found that water flow and flexible vegetation would interact with each other, and there were three water flow areas with different energy dissipation effects in the river with vegetation. Ree and plamer (1949) found that, when the vegetation was laid flat in the water flow, the top of the plant would be flat and orderly fall to one side. It was concluded that when the water flows through the flexible vegetation, the moving boundaries would occur.

In this experiment, artificial sea grasses were used to reduce the wave energy of dam break waves (simulated as tsunami waves). The characteristics of the dam break flow were investigated, the ball subjected to the dam break flow was observed, and some impact factors of ball climbing height were explored (Zheng et al., 2018). Finally, the energy dissipation coefficient of the sea grass in this experiment was investigated. The objective of this study is investigating the energy dissipation of the sea grass. This study aims at a better coastal protection by plants.

\section{Experimental set-up}

\subsection{Methodology}

In this experiment, three key experimental subjects were simulated as follows: 1) The dam break waves were generated in the fume to simulated as tsunami surges. 2) The steel balls were simulated as boulders (transported by tsunami surges). Therefore, the climbing height of the steel balls indicated the energy of tsunami surges. 3) Artificial sea grasses were simulated as real sea grasses, which were used to reduce the wave energy of dam break waves (simulated as tsunami waves). The characteristics of the dam break flow were investigated, the ball subjected to the dam break flow was observed, and some impact factors of ball climbing height were explored. Finally, the energy dissipation coefficient of the sea grass in this experiment was investigated. The dam break wave in this experiment is the gravity wave. Based on the plant height as a reference, the artificial grasses in the experiment were compared with different species of mangroves or sea grass in the coastal area (Yang et al., 2020; Zahermand et al., 2020). Therefore, the model scale was set as 1:50.

\subsection{Experimental flume}

The experiments were carried out in the hydraulic lab at Fuzhou University (Figure 1). The experimental flume was the multifunctional slope-changing flume with the size of $4400 \mathrm{~mm} \times 300 \mathrm{~mm} \times 300 \mathrm{~mm}$. The side walls 
on both sides are transparent, which is convenient for experimental observation. A water tank with the size of $3600 \mathrm{~mm} \times 550 \mathrm{~mm} \times 580 \mathrm{~mm}$ was built under the experimental flume for water supply and drainage, and an outlet was set at the end of the flume (He et al., 2018). The slope was set as 30 degrees, and the entire flume was a self-circulating device.

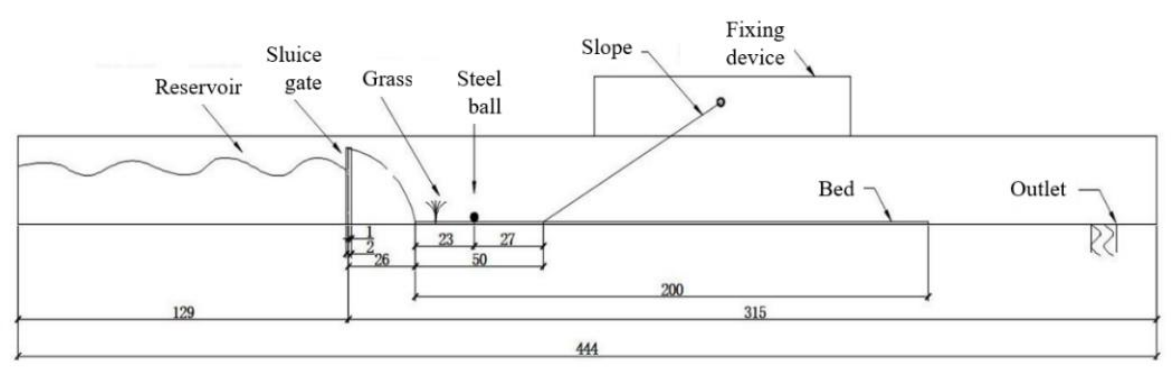

Figure 1. Schematic of the multi-function slope-changing flume

\subsection{Steel balls subjected to flows}

Four steel balls with different diameters were used in the experiment (Figure 2). Steel balls with diameters of $18 \mathrm{~mm}, 20 \mathrm{~mm}, 30 \mathrm{~mm}$, and $40 \mathrm{~mm}$ were selected. The density of the steel balls is $7900 \mathrm{~kg} / \mathrm{m}^{3}$. The masses of the steel balls were $25 \mathrm{~g}, 33 \mathrm{~g}, 112 \mathrm{~g}$, and $265 \mathrm{~g}$, respectively.

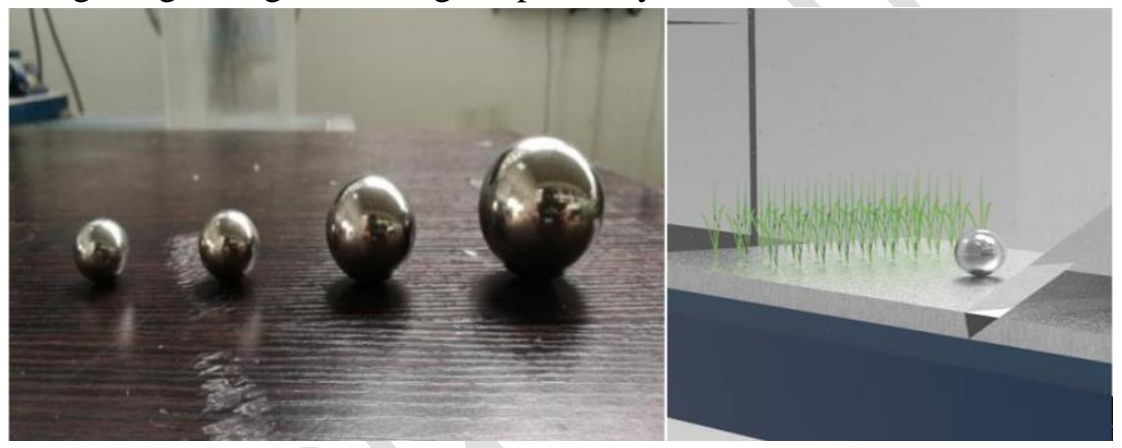

Figure 2. Photo of steel balls (left) and position of the ball in the flume (right)

\subsection{Energy dissipation plants}

In this experiment, three plastic artificial sea grasses were selected as energy dissipation plants. Because their branches and stems were relatively soft, they were regarded as flexible plants. The sea grasses were fixed at $410 \mathrm{~mm}$ downstream of the reservoir. As shown in Figure 3, according to the scale of 1:50, the heights of the artificial grass were $70 \mathrm{~mm}, 45 \mathrm{~mm}$ and $35 \mathrm{~mm}$, respectively, indicating that the actual plant heights were 3 $500 \mathrm{~mm}$ for Kandelia candel Druce, $2250 \mathrm{~mm}$ for Auicennia marina, and $1750 \mathrm{~mm}$ for Rhizophora Stylosa. Therefore, three types of simulated artificial grass were set in this flume, and each type contains three widths (Table 1).

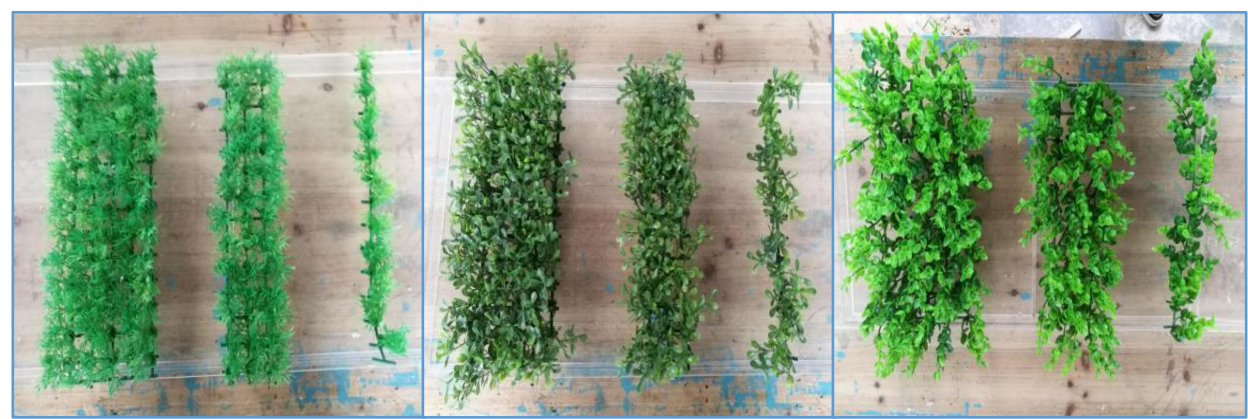

Figure 3. Photos of artificial sea grass 
Table 1. Energy dissipation plant set-up

\begin{tabular}{cccccc}
\hline \multirow{2}{*}{ Size } & \multirow{2}{*}{ Plant species } & \multirow{2}{*}{ Model height $(\mathrm{mm})$} & \multicolumn{3}{c}{ Total width $(\mathrm{mm})$} \\
\cline { 4 - 6 } & & 35 & 22 & 44 & 88 \\
\hline Small & Rhizophora Stylosa & 45 & 22 & 44 & 88 \\
Medium & Auicennia marina & 70 & 30 & 60 & 90 \\
Big & Kandelia candel Druce & & & \\
\hline
\end{tabular}

\subsection{Test conditions}

In the experiment, the water level of the reservoir was controlled by a water pump. The sluice gate fell down when the water level of the reservoir exceeds a target level. As a result, the strength of the dam break flow in the flume depends on the reservoir water level of the reservoir $(60 \mathrm{~mm}, 100 \mathrm{~mm}, 140 \mathrm{~mm}, 180 \mathrm{~mm}, 220 \mathrm{~mm})$, allowing different dam break flows to be generated in the flume (Cheshomi et al., 2020). The slope angle was fixed at 30 degrees, and the test conditions are summarized as follows:

(1) Reservoir water levels are $60 \mathrm{~mm}, 100 \mathrm{~mm}, 140 \mathrm{~mm}, 180 \mathrm{~mm}$, and $220 \mathrm{~mm}$;

(2) Plant types were as follows: no grass, small grass, middle grass, big grass, respectively (Table 1);

(3) The numbers of plant rows were 1, 3 and 5 rows, respectively;

(4) The diameters of the steel balls were $18 \mathrm{~mm}, 20 \mathrm{~mm}, 30 \mathrm{~mm}$, and $40 \mathrm{~mm}$, respectively;

(5) The initial locations of the steel balls were $270 \mathrm{~mm}, 320 \mathrm{~mm}, 350 \mathrm{~mm}, 380 \mathrm{~mm}, 410 \mathrm{~mm}, 440 \mathrm{~mm}$ in front of the slope, respectively.

Due to the errors of the experiment, each condition of the test was repeated at least 6 times, and the averaged value was adopted.

\section{Results}

\subsection{Wave height}

A steel ruler was erected next to the transparent flume. When the dam break flow passes the ruler at a constant speed, the maximum downstream water level was defined as the wave height. The wave heights at different reservoir water levels are listed in Table 2. As expected, the dam break wave height increases with increasing reservoir water level.

Table 2. Wave heights for different reservoir water levels

\begin{tabular}{cccccc}
\hline Reservoir water level $(\mathrm{mm})$ & 60 & 100 & 140 & 180 & 220 \\
\hline Wave height $(\mathrm{mm})$ & 12 & 24 & 35 & 44 & 54 \\
\hline
\end{tabular}

\subsection{Wave velocity}

Two water level gauges were set at an interval of $200 \mathrm{~mm}$ at test section in front of the slope. The first moment and the second moment were recorded when the water flow touches the first and second water gauges, respectively. A wave velocity was obtained by (distance/ time interval), which was considered to be uniform at a short distance. The wave velocities at different reservoir water levels are listed in Table 3. As expected, the dam break wave velocity also increases with increasing reservoir water level.

Table 3. Wave velocities for different reservoir water levels

\begin{tabular}{cc}
\hline Reservoir water level $(\mathrm{mm})$ & Average wave velocity $(\mathrm{m} / \mathrm{s})$ \\
\hline 60 & 0.72 \\
100 & 1.06 \\
\hline
\end{tabular}




\subsection{Froude number}

Froude numbers describe the rapidity of the water flow. For the tsunami wave on land or the dam break flow, the Froude number is usually larger than 1 . The Froude numbers for different reservoir water levels are listed in Table 4. In this experiment, the following formula was used for calculation:

$$
F r=\frac{v}{\sqrt{g h}}
$$

where, $\mathrm{Fr}$ is the Froude number, $v$ is the wave velocity, $h$ is the wave height, $g$ is the gravity acceleration. As Table 4 shows, the Froude number also increases with increasing reservoir water level. The Froude number changes from 2.11 to 3.01 , which applies to the tsunami wave.

Table 4. Froude number for different reservoir water levels

\begin{tabular}{cc}
\hline Reservoir water level $(\mathrm{mm})$ & $\operatorname{Fr}\left(g=9.81 \mathrm{~m} / \mathrm{s}^{2}\right)$ \\
\hline 60 & 2.11 \\
100 & 2.18 \\
140 & 2.20 \\
180 & 2.43 \\
220 & 3.01 \\
\hline
\end{tabular}

\subsection{Ball subjected to flow without sea grass}

Figure 4 shows the relationship between the reservoir water level and the ball climbing height for different ball diameters, without mitigation of the sea grass. As figure shows, the ball climbing height increases with increasing reservoir water level. Their relationship seems to be linear in our experimental range. As we expected, from the figure, it can be also seen that, the smaller the diameter of the ball is, the higher the ball will climb. Because the diameter of $18 \mathrm{~mm}$ and $20 \mathrm{~mm}$ are very close, their trend lines are also very close. For all cases, when the reservoir water level lower than $70 \mathrm{~mm}$, the dam break flow was too weak to carry the ball on the slope.

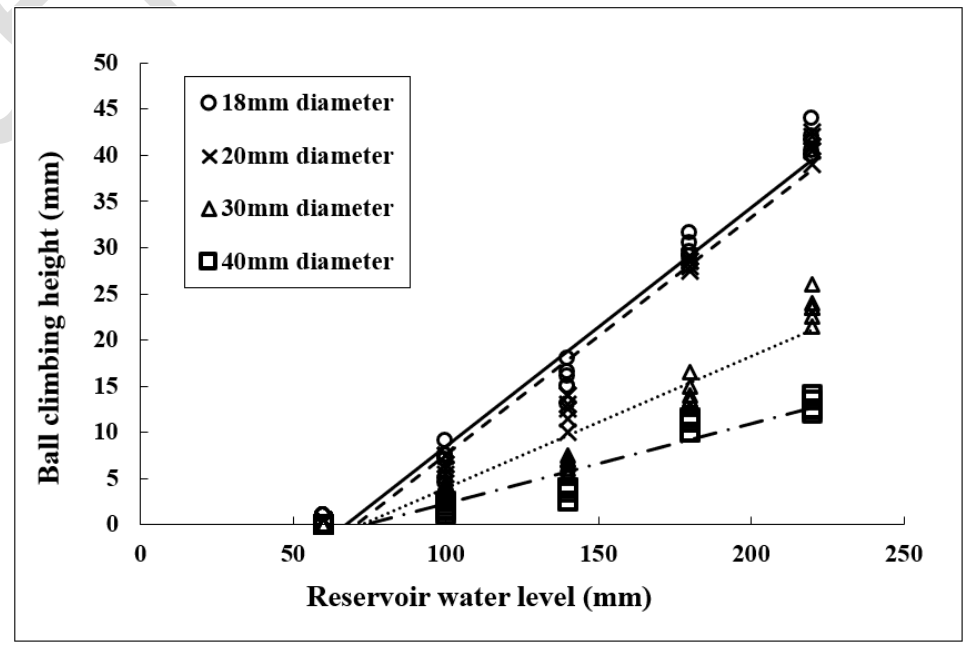

Figure 4. Relationship between reservoir water level and ball climbing height 


\subsection{Impact factor of initial position of ball}

In this study, the relative distance was denoted as (distance / reservoir water level), and the relative ball climbing height was denoted as (climbing height / reservoir water level). Figure 5 shows the relationship between the relative distance and the relative ball climbing height for different ball diameters. The distance of the ball in front of the slope depended on the initial location of the ball. Results show that, the relative ball climbing height decreases with increasing relative distance. This was because that, there was an energy loss for the dam break flow carrying the steel ball ( $\mathrm{Lu}$ et al., 2019). For example, for the steel ball of $40 \mathrm{~mm}$ diameter, the ball could not climb on the slope when the distance was longer than 1.7 times reservoir water level.

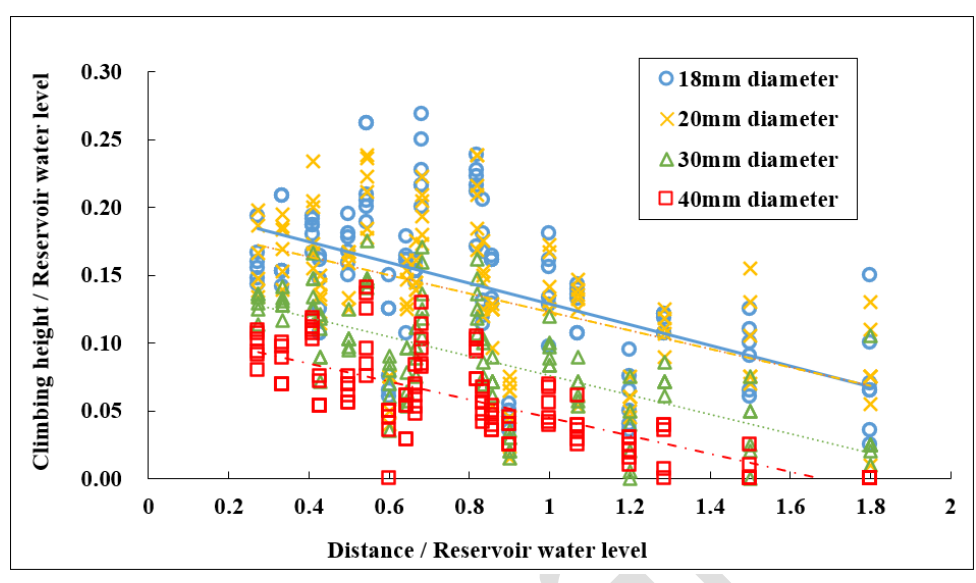

Figure 5. Relationship between initial position of the ball and ball climbing height

\subsection{Impact factor of sea grass}

The relative grass height was denoted as (grass height / reservoir water level). Figure 6 shows the relationship between the relative grass height and the relative ball climbing height. Results show that, the relative ball climbing height decreases with increasing relative grass height.

In general, the higher grass mitigates more energy than the lower grass for the same condition. However, it was different for the relative height of the grass. Note that, the trend line for smaller grass was more sloping than the trendline for bigger grass. To be more specific, for the same relative grass height (grass height / reservoir water level), the small grass mitigated more dam break flow energy than the big grass (Chen et al., 2017). This is because the rigidity of the small grass is bigger than that of the big grass.

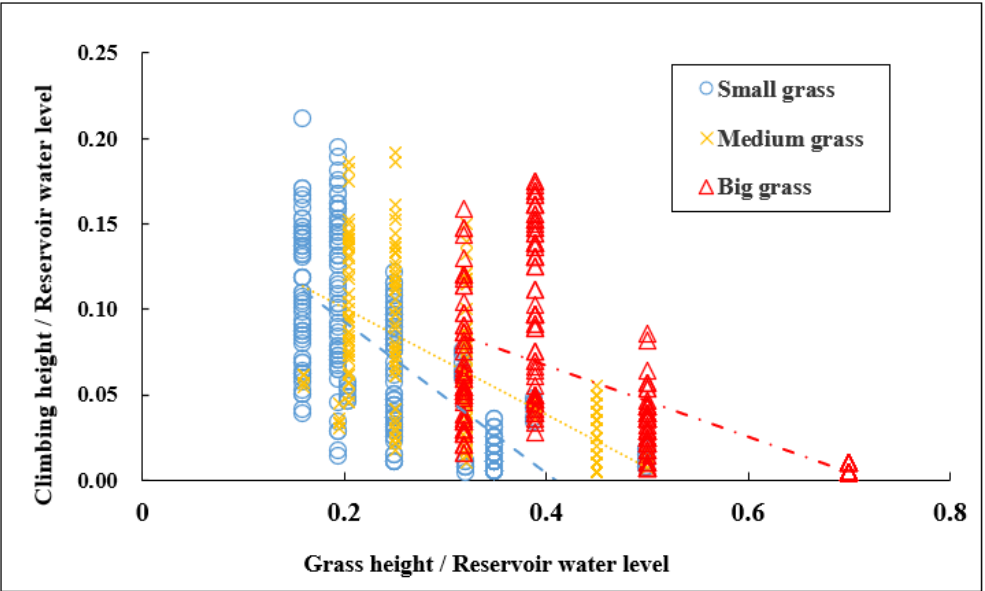

Figure 6. Climbing height of steel balls under plant energy dissipation 


\subsection{Impact factor of reservoir water level with sea grass}

The relative reservoir water level was denoted as (reservoir water level / ball diameter). Figure 7 shows the relationship between the relative reservoir water level and the relative ball climbing height for different sea grass types and different sea grass widths. Results show that, the relative ball climbing height increases with increasing relative reservoir water level. Their relationship appears to be logarithmic in general. When the relative reservoir water level was less than 2.5 , the dam break flow was too weak to carry the steel ball on the slope.

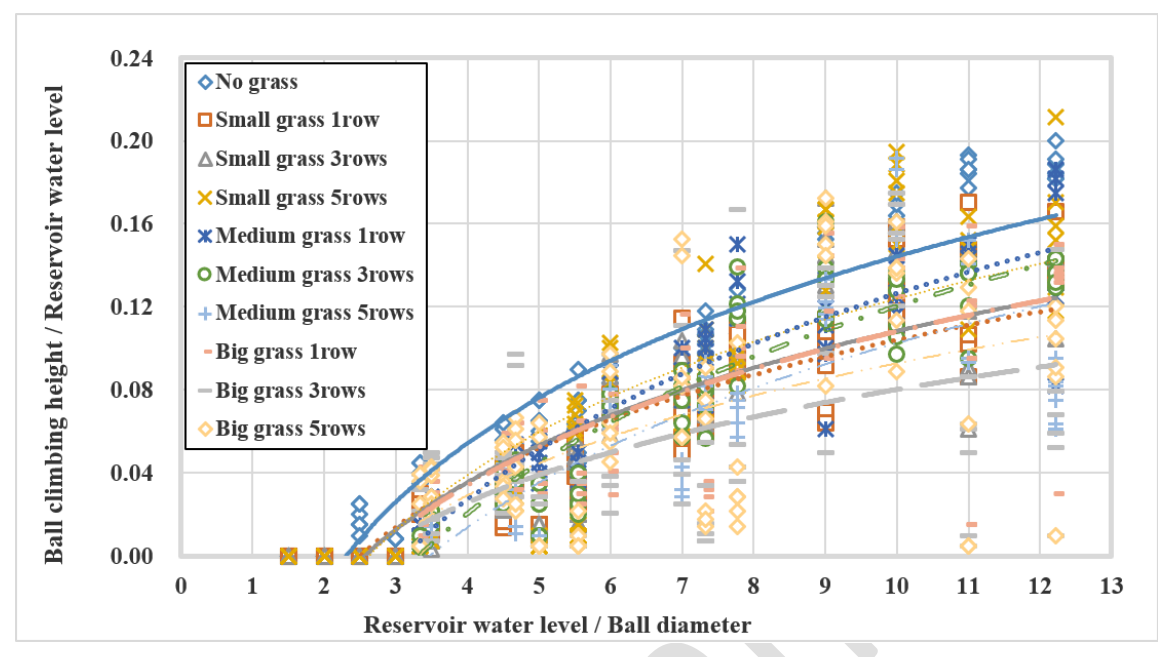

Figure 7. Relative climbing height of steel balls under energy dissipation of grass

\section{Discussion}

In this study, the energy dissipation coefficient needs to be proposed to describe the effectiveness of the energy mitigation of the sea grass. The energy dissipation coefficient is defined as follows:

$$
K=1-\frac{\text { Ball climbing height with sea grass }}{\text { Ball climbing height without sea grass }}
$$

It can be seen from the Eq. (2) that, the bigger $K$ is, the better the energy dissipation ability of the sea grass is. To make sure the Eq. (2) makes sense, the data with a denominator of zero was eliminated (for example, the climbing height was 0 for the reservoir water level of $60 \mathrm{~mm}$ ).

Figure 8 shows the energy dissipation coefficient for all tests. Results show that, the energy dissipation coefficient varies widely, changing from 0 to 0.93 , with the average value of 0.34 . Although the data were scattered, the energy dissipation coefficient changes with the reservoir water level in general. For different reservoir water level, the energy dissipation coefficient first decreases with increasing reservoir water level, and then increases with increasing reservoir water level. In our experimental range, the low point occurs at around $180 \mathrm{~mm}$ reservoir water level. 


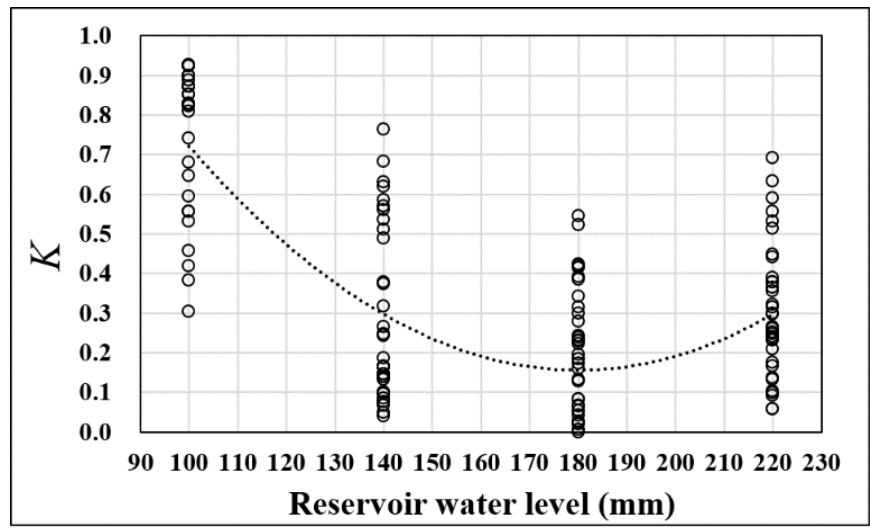

Figure 8. Energy dissipation coefficient for all test conditions

\section{Summaries and conclusions}

In this study, an experiment was conducted to investigate the energy dissipation of the sea grass in a dam break flume. A dam break flow was generated to simulated as tsunami surges, the steel balls were simulated as boulders (transported by tsunami), and the artificial sea grass was used as the energy dissipation plant. The characteristics of the dam break flow were investigated, the ball climbing heights were recorded to indicate the energy of tsunami surges, and the energy dissipation coefficient of the sea grass in this experiment was investigated. The results and conclusions are summarized as follows:

(1) For the reservoir water level changing from $60 \mathrm{~mm}$ to $220 \mathrm{~mm}$ in this study, the dam break wave height changed from $12 \mathrm{~mm}$ to $54 \mathrm{~mm}$; The dam break wave velocity changed from $0.72 \mathrm{~m} / \mathrm{s}$ to $2.19 \mathrm{~m} / \mathrm{s}$; The Froude number changed from 2.11 to 3.01, which applies to tsunami waves on land;

(2) Without mitigation of the sea grass, the ball climbing height increases with increasing reservoir water level and decreasing ball diameter, for $60-220 \mathrm{~mm}$ reservoir water levels and for $18-20 \mathrm{~mm}$ ball diameters;

(3) With the mitigation of the sea grass, the relative ball climbing height decreases with increasing relative distance and increasing relative grass height. The relative ball climbing height shows logarithmic correlation with relative reservoir water level. When the relative reservoir water level was less than 2.5 , the dam break flow was too weak to carry the steel ball on the slope.

(4) The energy dissipation coefficient of the sea grass changed with reservoir water level (ranged from 0 to 0.93 , with the average value of 0.34 ). The energy dissipation coefficient first decreases and then increases with increasing reservoir water level, with the low point at around $180 \mathrm{~mm}$ reservoir water level in our study.

It should be noted that, due to the limitation of the experimental facility and range, the energy dissipation coefficients were scattered. In the future, a better experimental set-up should be used to investigate the influences of the ball and the grass characteristics on the energy dissipation coefficient.

\section{Acknowledgments}

The work was financially supported by the National Natural Science Foundation of China (Grant No. 51809047); Fujian Provincial Natural Science Foundation (Grant No. 2019J05029).

\section{References}

Cao L. (2020). Changing port governance model: port spatial structure and trade efficiency, Journal of Coastal Research, 95(sp1), 963.

Chanson H. (2006). Tsunami surges on dry coastal plains: Application of dam break wave equations, Coastal Engineering Journal, 48(4), 355-370.

Chen C., Wang F.Y., Lin H. (2020). Experimental study on dam-break-like tsunami surge impact on small balls climbing on different slopes, Journal of Earthquake and Tsunami, 2, 2050022. 
Chen Y.Z., He L., Guan Y.L., et al. (2017). Life cycle assessment of greenhouse gas emissions and waterenergy optimization for shale gas supply chain planning based on multi-level approach: Case study in Barnett, Marcellus, Fayetteville, and Haynesville shales, Energy conversion and management, 134, 382398.

Cheshomi A., Bakhtiyari E., Khabbaz, H. (2020). A comparison between undrained shear strength of clayey soils acquired by "PMT" and laboratory tests, Arabian Journal of Geosciences, 13(64014).

Damarnegara S., Winarta B., Fuddoly L., et al. (2021). Numerical investigation of tsunami impact in newly developed tourism coast, case study: Melasti Beach, Physics and Chemistry of the Earth, Parts $A / B / C$, 12(103001).

Hafen H.V., Stolle J., Nistor I. et al. (2021). Side-by-side entrainment and displacement of cuboids due to a tsunami-like wave, Coastal Engineering, 164(103819).

He L., Chen Y.Z., Zhao H.H., et al. (2018). Game-based analysis of energy-water nexus for identifying environmental impacts during Shale gas operations under stochastic input, The Science of the Total Environment, 627, 1585-1601.

Jing X.B., Wang H.H., Wang H.L., et al. (2003). Behavior of drift by run-up tsunami and its acting force upon building on land, Journal of Vibration and Shock, 32(21), 41-46.

Kouwen N., Unny T.E., Hill H.M. (1969). Flow retardance in vegetated channels, Irrigation Drainage Division, 95, 329-342.

Lu H., Tian P., He L. (2019). Evaluating the global potential of aquifer thermal energy storage and determining the potential worldwide hotspots driven by socio-economic, geo-hydrologic and climatic conditions, Renewable \& Sustainable Energy Reviews, 112, 788-796.

Mizuno Y., Shibata K., Koshizuka S. (2021). Statistical analysis of three-dimensional run-up heights using gaussian process emulator of particle method, Computational Particle Mechanics, 1-11.

Mizurani N., Yamaguchi S., Tomita T., et al. (2005). Experimental study on behavior of container on apron due to tsunami and its impact load, ISOPE-2005 conference, proceeding of the 15th International Offshore and Polar Engineering Conference, Seoul, 640-645.

Ree W.O., Palmer V.J. (1949). Flow of water in channels protected by vegetative linings, Technical Bulletins, 967.

Yang L.W., Wang W.P., Zhang N., et al. (2020). Characteristics and numerical runout modeling analysis of the Xinmo landslide in Sichuan, China, Earth Sciences Research Journal, 24(2), 169-181.

Yeom G.S., Nakamura T., Mizutani N. (2009). Collision analysis of container drifted by runup tsunami using drift collision coupled model, Journal of Disaster Research, 4(6), 441-449.

Yeom G.S., Nakamura T., Usami A., Mizutani N. (2008). Study on estimation of collision force of a drifted container using fluid-structure interaction analysis, Annual Journal of Coastal Engineering, 55, 281-285.

Zahermand S., Vafaeian M., Bazyar M.H. (2020). Analysis of the physical and chemical properties of soil contaminated with oil (petroleum) hydrocarbons, Earth Sciences Research Journal, 24(2), 163-168.

Zhao X.J., Gu B., Gao F.K., et al. (2020). Matching model of energy supply and demand of the integrated energy system in coastal areas, Journal of Coastal Research, 103(sp1), 983.

Zheng W.K., Liu Y.T., Huang J.S., et al. (2018). Study on the optimal development method for offshore buried hill fractured reservoirs, Arabian Journal of Geosciences, 11(64020).

Zhu L., Kong L., Zhang C. (2020). Numerical study on hysteretic behaviour of horizontal-connection and energy-dissipation structures developed for prefabricated shear walls, Applied Sciences, 10(4), 1240. 